\title{
Forming Student Project Teams \\ Based on Hermann Brain Dominance (HBDI) Results
}

\author{
J. William Shelnutt, Silvia G. Middleton, Kimberly A. Buch; Monika Lumsdaine \\ UNC Charlotte/ Michigan Technological University
}

\begin{abstract}
The thinking preferences of 487 students at the University if North Carolina at Charlotte were evaluated with the Hermann Brain Dominance Instrument (HBDI) ${ }^{1}$ at the beginning of the fall 1995 term. These beginning engineering, computer science, and engineering technology students were grouped in teams of four to seven students for projects in their ENGR 1201 Introduction to Engineering Practice and Principles or EGET 3071 Professional Development in Engineering Technology courses. As much as possible the teams were multi-disciplinary. The engineering teams included computer science, electrical, mechanical, civil, and general (undeclared) majors; the engineering technology teams included electrical, mechanical, civil, and manufacturing engineering technology majors. Half of the teams in each of the two courses were selected with consideration of the HBDI profiles of the students in an attempt to form heterogeneous or so-called "whole-brain" teams; the other half of the teams had random distributions of thinking preferences. At the end of the term, the team projects (and the team learning process) were evaluated by faculty teams in order to test the hypothesis that heterogeneous teams as a whole will have better problem-solving outcomes even when the homogeneous student teams have been taught about thinking preferences and their implications for group dynamics and communications. This is an important issue: can the cost and labor involved in using the HBDI (especially at the freshman level) be justified by its contribution to improved team outcomes?
\end{abstract}

This paper reports the preliminary findings of the first phase of a longitudinal study at UNC Charlotte examining the relationships between the make-up of thinking style profiles of teams and the outcomes they produce. The current study attempts to validate earlier studies of the thinking preferences of engineering students conducted at the University of Toledo ${ }^{2}$. The study will add detailed quantitative and qualitative assessment data over a five year projected course. This paper reports initial anecdotal findings; early statistical assessment will be available at the ASEE '96 Annual Conference.

Introduction. As part of the new curriculum development initiative in the William States Lee College of Engineering at the University of North Carolina at Charlotte, the faculty has developed three experimental courses designed to incorporate team-building skills at the outset of the students' experience: Introduction to Engineering Practice and Principles I, II (ENGR 1201, 1202), and Professional Development in Engineering Technology (EGET 3071). These courses include team projects as well as individual assignments as vehicles for learning team skills, self development tools such as The Seven Habits of Highly Successful

People $^{3}$, and the use of the Meyers Briggs Type Indicator (MBTI) and the Hermann Brain Dominance Instrument (HBDI) as self awareness tools and for structuring teams. The courses, tools and measures used to assess the results are described in this paper. The authors focused, in particular, on the HBDI as a tool for self awareness and as a potential method for enhancing team performance by facilitating creation of teams balanced in thinking preference, or what is referred to as "whole brain" teams. The HBDI will also be used to assess the changes in thinking preferences of the students in these teams, as measured by the instrument, as they move 
through the curriculum and graduate. Students will complete the instrument during their first semester and again during their last semester of enrollment prior to graduation during this longitudinal study.

The Hermann Brain Dominance Instrument (HBDI) Scores and profiles on the HBDI describe levels of preference for four different major modes or quadrants of thinking, which are characterized by a combination of left or right brain thinking, and limbic or cerebral thinking ${ }^{1}$. The left-brain cerebral quadrant, A, shows a preference for mathematical, technical, logical, factual, and analytical thinking styles. The left-brain limbic quadrant, B, shows a preference for organizational, planned, conservative, controlled, and administrative thinking. The right-brain limbic quadrant, C, shows a preference for interpersonal, musical, talking, emotional, and spiritual thinking. The right-brain cerebral quadrant, D, shows a preference for imaginative, holistic, conceptual, artistic and synthesizing thinking. As might be expected, engineering faculty and students tend to have higher scores in quadrant A (and often B), and lower scores in quadrant C. Table 1 gives the average distributions for the classes used in this study.

\begin{tabular}{|c|c|c|c|c|c|c|c|}
\hline Class & $\begin{array}{c}\text { Section } \\
\text { Size }\end{array}$ & $\begin{array}{c}\text { Quadrant } \\
\text { A } \\
\text { Average }\end{array}$ & $\begin{array}{c}\text { Quadrant } \\
\text { B } \\
\text { Average }\end{array}$ & $\begin{array}{c}\text { Quadrant } \\
\text { C } \\
\text { Average }\end{array}$ & $\begin{array}{c}\text { Quadrant } \\
\text { D } \\
\text { Average }\end{array}$ & $\begin{array}{c}\text { \% } \\
\text { Quadrant } \\
\text { C } \\
\text { Avoiders }\end{array}$ & $\begin{array}{c}\text { \% Multi- } \\
\text { dominant }\end{array}$ \\
\hline $1201-001$ & 167 & 88 & 77 & 54 & 66 & 11 & 19 \\
$1201-002$ & 164 & 87 & 77 & 53 & 70 & 9 & 19 \\
$1201-090$ & 82 & 84 & 76 & 53 & 74 & 12 & 27 \\
\hline 1201 Avg. & 413 (Total) & 87 & 77 & 54 & 69 & 10 & 21 \\
\hline $3071-001$ & 14 & 89 & 83 & 51 & 84 & 25 & 25 \\
$3071-002$ & 34 & 81 & 81 & 52 & 67 & 19 & 19 \\
$3071-004$ & 32 & 87 & 80 & 51 & 68 & 26 & 6 \\
$3071-005$ & 7 & 84 & 80 & 52 & 74 & 17 & 17 \\
\hline 3071 Avg. & 87 (Total) & 85 & 81 & 52 & 67 & 22 & 15 \\
\hline
\end{tabular}

Table 1. HBDI Results for Fall 1995 classes.

Ned Hermann examined the characteristics desired for success from the 1960's to the present. He determined that the current paradigm is a long-range global one ${ }^{1}$, which implies strengths in quadrants $C$ and $D$, in addition to the strong analytical skills of quadrant A. Employers want innovative engineers and technologists who can see the big picture, can work effectively in teams, can express themselves in a variety of situations, and can integrate into engineering design environmental, ethical and social concerns. However, the heavily analytical and rote problem solving orientation of current engineering curricula typically leads to neglect of development of these needed skills.

Longitudinal studies of 1990-93 fall freshmen and 1991-94 spring senior classes in the College of Engineering at the University of Toledo using the HBDI showed that students must be given direction to develop 
quadrant $\mathrm{C}$ and $\mathrm{D}$ skills $^{2,4}$. The HBDI results showed a shift from the more rote quadrant $\mathrm{B}$ thinking to an increase in quadrant $\mathrm{D}$ thinking primarily as a result of a new creative problem-solving course. However, the Lumsdaines found that the avoidance of quadrant $\mathrm{C}$ thinking persisted, resulting in somewhat uncomfortable classroom climates for some students, particularly many among the most talented and creative and many female students. Therefore, work is still needed to encourage students in technical disciplines to develop a comfortable use of the thinking styles available to them, preferably through curriculum integration of these skills.

Second year results recently obtained have confirmed the original findings. Data was also gathered for seniors in the metallurgy capstone design class at Michigan Technological University in 1994-95. The instructors were most impressed with the results of teams who had the strongest right-brain thinking preferences. The UNC Charlotte project is designed to provide additional, more detailed quantitative and qualitative assessment and comparison to this earlier, more limited study.

Curriculum Development Objectives. Studies throughout the literature certify the need for early student involvement in design to encourage retention. The studies at the University of Toledo showed that a disciplined approach to teaching teamwork and personal development was needed as well. The faculty at UNC Charlotte decided to include these elements as major pieces of the new courses being developed for entering students, also including traditional topics of professionalism and introducing basic computer skills.

All entering students in engineering and computer science are required to successfully complete ENGR 1201. This two credit-hour course includes four modules: Introduction to the College and Profession (15\%), Introduction to Computing (15\%), Introduction to Mentoring and Teamwork (15\%), and Team Projects (45\%). The course is team-taught, with faculty from each department involved. The HBDI was used to form the teams for the semester, which were multi-disciplinary. The team projects were also interdisciplinary in nature. The teams in ENGR 1202, offered first in the spring 1996 semester, are disciplinary, as are the projects. This is intended to assist in the formation of "base groups," or teams of students that move through the curriculum together. The class focuses further on the development of team and design skills, with a laboratory for the disciplinary work.

All entering students in the engineering technology program are required to complete EGET 3071. Offered for the first time in the fall of 1995, this one credit-hour course taught team skills and organized the teams to learn eight computer programs on the college's networked computing system and to produce a final report. The programs included applications such as AutoCAD, word processing, spreadsheets, and research skills. Teams were formed for these classes as with ENGR 1201.

Team Formation. A brief description of whole-brain team formation methodology is given here. For a complete description of the four quadrants and the thinking and learning styles associated with them, please refer to Lumsdaine ${ }^{2,4}$. Half of the teams in each course (ENGR 1201 and EGET 3071) were selected using the HBDI profiles of the students in an attempt to form whole-brain teams. The other teams had a random distribution of thinking preferences.

The instructors wished to determine if there was a value to assigning teams based on the HBDI. Therefore a double-blind study was done in which neither students nor instructors knew which teams were balanced and which were random, according to the HBDI results. In order to assign teams with no obvious bias, the class rolls were first randomized with a random number generator, and split into halves. Teams of six or seven members were assigned within each group, one randomly, the other by the process below:

1. Assign four team members based on $\mathrm{A}, \mathrm{B}, \mathrm{D}$, and $\mathrm{A}+\mathrm{B}$ quadrant dominance, attempting to balance between the disciplines.

2. Add at least one multi-dominant or whole brain thinker.

3. Add at least one student with a preference in $\mathrm{C}$, if not already present. 
Ensure that no more than one $\mathrm{C}$ avoider is present, reassigning members as needed.

The resulting assignments are summarized in Table 2. Smaller team sizes were used as necessary in smaller sections to avoid having one very large or very small team. Students who had not completed the HBDI in time for consideration of their scores were added as the last member of a team.

\begin{tabular}{|l|c|l|c|c|c|}
\hline Section & Enrollment & $\begin{array}{c}\text { Team } \\
\text { Type }\end{array}$ & $\begin{array}{c}\text { \# 7-Member } \\
\text { Teams }\end{array}$ & $\begin{array}{c}\text { \# 6-Member } \\
\text { Teams }\end{array}$ & $\begin{array}{c}\text { \# 5-Member } \\
\text { Teams }\end{array}$ \\
\hline $1201-001$ & 167 & Random & 6 & 7 & \\
\hline $1201-002$ & 164 & Ralanced & 5 & 8 & \\
\hline $1201-090$ & 82 & Random & 4 & 9 & \\
& & Balanced & 4 & 9 & \\
\hline $3071-001$ & 14 & Random & 1 & 6 & \\
& & Balanced & 1 & & 1 \\
\hline $3071-002$ & 34 & Random & & 2 & 2 \\
& & Balanced & & 1 & 2 \\
\hline $3071-004$ & 32 & Random & & & 1 \\
\hline $3071-005$ & 7 & Random & 1 & & \\
\hline
\end{tabular}

Table 2. Initial Teams Composition, Fall 1995

Development of Team Skills. Semester-long team projects were used as the primary arena in which team skills were to be developed. Each team was charged with completing a project and producing a report. The engineering technology students were to teach each other to use eight computer programs with the aid of a video and some on-line tutorials. The engineering and computer science students were required to complete a conceptual design project, in addition to showing proficiency on five computer programs. The interdisciplinary team of faculty charged with teaching ENGR 1201 settled on a project topic of "Conceptual Design of an Elevator System for Tall Buildings." The attraction of this topic was its interdisciplinary nature, familiarity of the students with the product, and a potential for a reasonably simple design. However, many teams quickly discovered that elevator systems can be quite complex, and several explored very innovative approaches to design and installation for both new construction and for retrofitting existing structures The teams were asked to act as though they were entrepreneurial teams creating a design for presentation to a group of investors - not engineers. By posing the problem in this fashion the attention was shifted away from the complex technical design details and into the creative mode, which was the approach desired. This also afforded the teams opportunities to inquire into the needs of prospective customers (e.g. building owners, architects, engineers, and every day users of elevators), fostering data collection and holistic thinking, as well as using this information to invent creative solutions to these problems. 
An important part of the charge to the student teams was that they were each individually responsible for their team's performance. A large portion of each student's final grade was determined by the quality of the team's work. In addition the students were asked to do anonymous peer evaluations at both their mid-term and final points of the semester, with the final evaluation used in determining each student's grade.

Because of the emphasis on individual responsibility within the team the groups took quite seriously the task of finding their team members. When e-mail did not result in the desired team meeting, the students appeared in the class with signs bearing the team name and gathered after class to create their operating schedule. However, students withdrawing late often frustrated teams who tried to become effective early in the semester. Although some teams requested reassignment of a non-performing member, in effect firing them, the instructors uniformly declined to grant these requests. The teams were required to handle these situations within their own ranks.

Each team generated and adopted a set of "ground rules" to guide its activities. Many teams used an adaptation of model ground rules distributed, which included such things as being on time, preparing an agenda, taking minutes, keeping a list of assignments and deadlines, giving each other respect, and "Seeking first to understand, then be understood." 3 Each student was assigned readings in a textbook on high performance teams by Lundy ${ }^{5}$, both as a way to suggest effective team dynamics and as a source of insight on ways to enhance individual contributions to a team effort.

Further, the ENGR 1201 teams were taught design tools, such as the Pugh Method ${ }^{4}$, to model an effective method of comparing design alternatives. This method lends itself very well to the potential for creative team-based design by comparing several independently created solutions to some base or standard design in a first round. The second round promotes "borrowing" from each other's ideas to develop the "best" design by the proposed criteria. Students became quite involved in this process, so that the designs emerging after round two were close to the final team design adopted.

An important part of team development was personal awareness and development. The authors believe that both aspects are critical to an individual's ability to function effectively, in a team or otherwise. Early in the ENGR 1201 course each student was required to read Covey's widely acclaimed book, The Seven Habits of Highly Successful People and to write a paper on use of each of the habits by themselves or someone else they knew. This provided the framework for using other awareness and development tools, such as the Meyers Briggs and HBDI. Students were encouraged to share their individual results with their teams and were required to create an approximate team profile to facilitate discussion of individual strengths and weaknesses in regards to team operation.

Assessment Measures. Individual and team assessments were used throughout to determine the effectiveness of the students and the courses. Peer appraisals, grades on team and individual assignments, selfreported development plans, and final written and oral report grades were used in assigning grades. The overall grade distribution was heavily weighted with grades of $\mathrm{A}$ and $\mathrm{B}$, though there were some grades of $\mathrm{C}, \mathrm{D}$ and $\mathrm{F}$ earned by individuals. Peer evaluations, done via the College computing system, were often the most significant determining factor in overall team member's grade differentiation. The faculty team commissioned a student to develop a Netscape-based program for this evaluation procedure, which allowed the faculty to view identifying information on both sender and recipient, but stripped off sender ID before the recipient saw the evaluations. Many teams noted increased participation by team members receiving unfavorable mid-term peer evaluations, proving their effectiveness in providing meaningful feedback.

Team accountability plans due during week eleven provided a strong early feedback of team success. Three teams showed some disorganization with more than one report handed in; the state of disorganization was clearly illustrated by the disagreement between reports of each team's status. Most teams indicated good

$$
1996 \text { ASEE Annual Conference Proceedings }
$$


progress in becoming effective, though not highly so. One surprise was the difference in performance between the three section of ENGR 1201. Section 090 was held later in the evening, with a start time of 5:00 PM to accommodate part-time students who were employed in the community. The authors initially anticipated that these students would be more dedicated and effective with their time, producing better results faster. In fact, the opposite situation occurred; whether through lack of time or commitment, these students usually lagged behind the other two groups in both quality and quantity of output.

Several teams in the outstanding category for team accountability referred to a dual mission, both project design and expectation of learning and practicing team skills. Although an exhaustive comparison of team assessment reports and team mission statements has not been made, it is anticipated that a close correlation will exist for outstanding ratings on both assignments.

One assessment of the course is that the mid-term withdrawal rate seemed to be about $40 \%$ of the withdrawal rate for the more traditional Introduction to Engineering course offered previously. A lengthy course evaluation was done as part of the final exam. An initial scan of the survey indicates a high rate of satisfaction with the course. Full analysis is not yet complete; details will be available at the ASEE Annual Conference.

Faculty from all five departments in the College were involved in assessing the oral project reports. Although the faculty had indicated skepticism that the course would produce any useful results, most were quite impressed with the presentations, both in content and quality. Results from these evaluations are being tabulated along with the results of the written presentations. These two are the major measurements of team success. Other measures to be compared for the two groups are team effectiveness reports, individual and team average course grades, and peer evaluations. This data will be compiled every semester for the duration of the five-year study, using interim results to guide the team in adjusting course content and assignments for maximum effectiveness.

Future Work. The HBDI has been administered to a small number of faculty and staff in the William States Lee College of Engineering and an average profile has been developed. As expected, the profile shows primary strengths in quadrants $\mathrm{A}$ and $\mathrm{B}$, but also in $\mathrm{D}$, indicating the creativity associated with research. In the future more faculty will be encouraged to participate, both to inform them of their own thinking (and therefore teaching) style and to educate them about the diversity in thought processes between faculty and students.

The authors intend to administer the HBDI to graduating seniors for the 1996 academic year to benchmark the dominant thinking styles of the student body at UNC Charlotte with the current, more traditional curriculum. The contiuing study begun with students entering in the fall of 1995 will help assess the effects of the major curriculum changes currently being undertaken. Of particular interest will be the retention of students with strong thinking styles in $\mathrm{C}$ and $\mathrm{D}$ quadrants and the development of these thinking styles in students whose major strength is in quadrant $\mathrm{A}$ or with strengths in quadrants $\mathrm{A}$ and $\mathrm{B}$.

Although it is too early to draw any conclusions about the effectiveness of the HBDI in forming teams, there is evidence that it has significant value as a self-awareness tool in developing team and individual skills. One author uses the results of the HBDI in counseling students about academic and career issues. For many students this is a first serious look at their thinking and learning styles and can be a strong personal affirmation. For several it has given them an indication that success in a technical career is well within their reach but will require additional effort to focus on Quadrant A, which is not a dominant mode for them. This has helped the College in promoting diversity in thought styles within its student body. This may prove to be the most valuable contribution of the instrument, though continuing research will assert its value in team formation. 


\section{References}

1. Hermann, Ned; The Creative Brain; Brain Books; Lake Lure, North Carolina; 1990.

2. Lumsdaine, Monika and Lumsdaine, Edward; “Thinking Preferences of Engineering Students: Implications for Curriculum Restructuring"; Journal of Engineering Education; American Society for Engineering Education; April 1995.

3. Covey, Stephen; The Seven Habits of Highly Successful People; Simon and Schuster; 1989.

4. Lumsdaine, Edward and Lumsdaine, Monika; Creative Problem Solving; McGraw Hill; 1995.

Lundy, James L.; TEAMS: How to Develop Peak Performance Teams for World Class Results; Dartnell Press; Chicago, Illinois; 1992.

\section{Biographical Information}

J. William Shelnutt is an Associate Professor of Engineering Technology at the University of North Carolina at Charlotte. He was the lead faculty member for both ENGR 1201 and EGET 3071 for the Fall 1995 semester and was instrumental in the development of both courses.

Silvia G. Middleton is Assistant Dean and Adjunct Assistant Professor of Electrical Engineering at UNC Charlotte. She was the secondary faculty member for ENGR 1201 and is responsible for the College's recruiting and retention programs, including development of the freshman curriculum.

Kimberly Buch is an Associate Professor of Psychology at the University of North Carolina at Charlotte. She has been involved in a number of activities with the William States Lee College of Engineering, including the formation of faculty and administrative teams to develop the College mission and vision statements.

Monika Lumsdaine is a Visiting Scientist at Michigan Technological University. She has co-authored numerous papers and a book about creative problem solving and the application of the HBDI to team formation and assessment. She is also the president of E\&M Lumsdaine Solar Consultants, Inc. 